\title{
The association between sex-related interleukin-6 gene polymorphisms and the risk for cerebral palsy
}

Dan Bi ${ }^{1,7 \dagger}$, Mingjie Chen ${ }^{2 \dagger}$, Xiaoli Zhang ${ }^{1}$, Honglian Wang ${ }^{2}$, Lei Xia ${ }^{1}$, Qing Shang ${ }^{3}$, Tongchuan $\mathrm{Li}^{1}$, Dengna Zhu ${ }^{1}$, Klas Blomgren ${ }^{4,5}$, Lin He ${ }^{2,6}$, Xiaoyang Wang ${ }^{1,7}$, Qinghe Xing ${ }^{2^{*}}$ and Changlian Zhu ${ }^{1,5^{*}+}$

\begin{abstract}
Background: The relationship between genetic factors and the development of cerebral palsy (CP) has recently attracted much attention. Polymorphisms in the genes encoding proinflammatory cytokines have been shown to be associated with susceptibility to perinatal brain injury and development of CP. Interleukin-6 (IL-6) is a proinflammatory cytokine that plays a pivotal role in neonatal brain injury, but conflicting results have been reported regarding the association between IL-6 single nucleotide polymorphisms (SNPS) and CP. The purpose of this study was to analyze IL-6 gene polymorphisms and protein expression and to explore the role of IL-6 in the Chinese CP population.

Methods: A total of 753 healthy controls and 713 CP patients were studied to detect the presence of five SNPs (rs1800796, rs2069837, rs2066992, rs2069840, and rs10242595) in the IL-6 locus. Of these, 77 healthy controls and 87 CP patients were selected for measurement of plasma IL-6 by Luminex assay. The SHEsis program was used to analyze the genotyping data. For all comparisons; multiple testing on each individual SNP was corrected by the SNPSpD program.

Results: There were no differences in allele or genotype frequencies between the overall CP patients and controls among the five genetic polymorphisms. However, subgroup analysis found significant sex-related differences in allele and genotype frequencies. Differences were found between spastic CP and controls in males for rs2069837; between CP with periventricular leukomalacia and controls in males for rs1800796 and rs2066992; and between term CP and controls in males for rs2069837. Plasma IL-6 levels were higher in CP patients than in the controls, and this difference was more robust in full-term male spastic CP patients. Furthermore, the genotype has an effect on IL-6 synthesis.
\end{abstract}

Conclusions: The influence of IL-6 gene polymorphisms on IL-6 synthesis and the susceptibility to CP is related to sex and gestational age.

Keywords: Cytokine, Inflammation, Periventricular leukomalacia, Single nucleotide polymorphisms

\section{Introduction}

Cerebral palsy $(\mathrm{CP})$ is a group of non-progressive motor impairment syndromes caused by lesions during early brain development that often include cognitive deficits and musculoskeletal dysfunction [1,2]. The prevalence of $\mathrm{CP}$ - around 2 to 3 cases per 1,000 live births - has been stable over the past 30 years [3]. CP has become the

\footnotetext{
* Correspondence: xingqinghe@hotmail.com; changlian.zhu@neuro.gu.se ${ }^{\dagger}$ Equal contributors

${ }^{2}$ Children's Hospital and Institutes of Biomedical Sciences, Fudan University, 130 Dong'an Road, 200032 Shanghai, China

'Department of Pediatrics, The Third Affiliated Hospital of Zhengzhou University, 7 Kangfu Street, 450052 Zhengzhou, China

Full list of author information is available at the end of the article
}

leading cause of childhood disability in both developing and developed countries $[4,5]$, but the vast majority of the underlying pathogenic factors behind the development of $\mathrm{CP}$ are still unknown. Risk factors for $\mathrm{CP}$ have been categorized as prenatal, perinatal, and postnatal, but the majority of the risk factors - about $70 \%$ to $80 \%$ - occur prenatally [6]. Prenatal inflammation, such as intrauterine inflammation, is believed to be an important causal factor of adverse neurological outcomes [7], and an abnormal cytokine response has been suggested to be a common pathway for inducing brain injury [8].

Interleukin-6 (IL-6) is a pro-inflammatory cytokine that responds to intrauterine infection by inducing further 
increases in cytokine production [8]. Studies have shown that IL-6 is linked to clinical chorioamnionitis and preterm birth and that there is a three-fold increased risk for the development of periventricular leukomalacia (PVL) in preterm infants $[9,10]$. The $I L-6$ single nucleotide polymorphism (SNP) rs1800795 (G-174C) was reported to be associated with disabling brain injury but not cognitive development in 148 children who were born at less than 32 weeks gestational age in the UK [9]. Additionally, a population-based case-control study including 334,333 infants showed that rs1800795 is a risk factor for CP among term and near-term infants who were born at more than 36 weeks gestational age in the US [11,12]. However, with comparable gestational age distributions in $\mathrm{CP}$ patients and control groups, conflicting results showed no association between CP and rs1800795 in 144 very preterm infants who were born at less than 32 weeks gestational age in Croatia [13]. The conflicting results might be based on differences in sample size or could indicate that the effect of $I L-6$ gene function in the development of CP might be influenced by ethnicity or gestational age. Based on a replicate genetic study on SNPs from different regions of the $I L-6$ gene, we have previously reported that the SNP rs2069837 is associated with male spastic $\mathrm{CP}$ in the Chinese Han population. To further confirm the risk factors associated with SNPs and to validate the regulation of IL-6 by the SNPs [10], we used a larger sample size to analyze five polymorphisms from different regions of the $I L-6$ gene and combined this with a plasma IL-6 protein assay to evaluate the importance of IL-6 in the etiology of CP.

\section{Methods}

\section{Subjects}

The study population consisted of $713 \mathrm{CP}$ patients (219 girls $(30.7 \%)$ and 494 boys (69.3\%) with a mean age \pm SD of $19.1 \pm 14.9$ months) chosen from centers for CP rehabilitation in the Third Affiliated Hospital of Zhengzhou University and Zhengzhou Children's Hospital from 1 July 2010 to 31 May 2012 (Table 1). Of these, 87 $\mathrm{CP}$ patients (54 boys $(62.1 \%)$ and 33 girls $(37.9 \%)$ with a mean age \pm SD of $19.9 \pm 14.1$ months) were selected for the serum IL-6 assay (Table 2). The 753 healthy control participants (262 girls (34.8\%) and 491 boys (65.2\%) with a mean age \pm SD of $19.6 \pm 18.5$ months) were chosen from the Child Healthcare Departments at the same hospitals during the same period. Of these healthy controls, 77 (63 boys $(81.8 \%)$ and 14 girls (18.2\%) with a mean age \pm SD of $19.8 \pm 12.4$ months) were selected for the serum IL-6 assay. Blood samples were collected into tubes containing EDTA by skilled nurses on the second day of being hospitalized. Plasma was separated by centrifugation $(1,500 \times g$ for $15 \mathrm{~min})$ at room temperature within 2 hours after being collected. DNA was obtained
Table 1 Sample description for gene polymorphism analysis

\begin{tabular}{|c|c|c|c|c|}
\hline \multirow[t]{2}{*}{ Characteristic } & \multicolumn{2}{|c|}{ CP cases } & \multicolumn{2}{|c|}{ Control } \\
\hline & Total (\%) & $M / F(n)$ & Total (\%) & $M / F(n)$ \\
\hline \multicolumn{5}{|l|}{ Type of CP } \\
\hline Spastic CP & $456(64.0)$ & $325 / 131$ & - & - \\
\hline Non-spastic CP & $257(36.0)$ & $169 / 88$ & - & - \\
\hline Total & $713(100)$ & $494 / 219$ & $753(100)$ & $491 / 262$ \\
\hline \multicolumn{5}{|l|}{ Gestational age } \\
\hline Term ( $\geq 37$ weeks) & $496(69.6)$ & $338 / 158$ & $742(98.5)$ & $481 / 261$ \\
\hline Preterm (<37 weeks) & $217(30.4)$ & $156 / 61$ & $11(1.5)$ & $10 / 1$ \\
\hline Total & $713(100)$ & $494 / 219$ & $753(100)$ & $491 / 262$ \\
\hline \multicolumn{5}{|l|}{ Birth weight } \\
\hline$\geq 2,500 \mathrm{~g}$ & $552(77.4)$ & $390 / 162$ & 731 (97.1) & $475 / 256$ \\
\hline$<2,500 \mathrm{~g}$ & $161(22.6)$ & $104 / 57$ & $22(2.9)$ & $16 / 6$ \\
\hline Total & $713(100)$ & $494 / 219$ & $753(100)$ & $491 / 262$ \\
\hline \multicolumn{5}{|l|}{ Birth asphyxia } \\
\hline No asphyxia & $484(67.9)$ & $326 / 158$ & $741(98.4)$ & $482 / 259$ \\
\hline Asphyxia & $229(32.1)$ & $168 / 61$ & $12(1.6)$ & $9 / 3$ \\
\hline Total & $713(100)$ & $494 / 219$ & $753(100)$ & $491 / 262$ \\
\hline \multicolumn{5}{|l|}{ Complication } \\
\hline With PVL & $75(10.5)$ & $56 / 19$ & - & - \\
\hline Without PVL & $638(89.5)$ & $438 / 200$ & - & - \\
\hline With MR & $274(38.4)$ & $185 / 89$ & - & - \\
\hline Without MR & $439(61.6)$ & $309 / 130$ & - & - \\
\hline With HIE & $342(48.0)$ & $245 / 97$ & - & - \\
\hline Without HIE & $371(52.0)$ & 249/122 & - & - \\
\hline \multicolumn{5}{|l|}{ Maternal factors } \\
\hline PROM & $88(12.3)$ & $62 / 26$ & $14(1.9)$ & $11 / 3$ \\
\hline No PROM & $625(87.7)$ & $432 / 193$ & 739 (98.1) & $480 / 259$ \\
\hline TPL & $57(8.0)$ & $42 / 15$ & $23(3.1)$ & $17 / 6$ \\
\hline No TPL & $656(92.0)$ & $452 / 204$ & 730 (96.9) & $474 / 256$ \\
\hline $\mathrm{PlH}$ & $35(4.9)$ & $23 / 12$ & $14(1.9)$ & $12 / 2$ \\
\hline $\mathrm{No} \mathrm{PIH}$ & 678 (95.1) & $471 / 207$ & 739 (98.1) & $479 / 260$ \\
\hline
\end{tabular}

$\mathrm{CP}$, cerebral palsy; $\mathrm{M}$, male; $\mathrm{F}$, female; $\mathrm{PVL}$, periventricular leukomalacia; $\mathrm{MR}$, mental retardation; $\mathrm{HIE}$, hypoxic ischemic encephalopathy; $\mathrm{PROM}$, premature rupture of membrane; TPL, threatened premature labor; $\mathrm{PIH}$, pregnancy-induced hypertension.

from the remaining blood components from the same sample. All the prepared samples were immediately stored at $-70^{\circ} \mathrm{C}$. All subjects were Han Chinese from the Henan Province, and written informed consent to participate in this study was provided by the children's parents. Child neurologists diagnosed and classified the $\mathrm{CP}$ by clinical examination or by using medical records, including brain imaging, according to the guidelines proposed by the "Surveillance of CP in Europe" network [14]. Children in either the $\mathrm{CP}$ or control group with myopathy or metabolic anomalies were excluded from 
Table 2 Sample description for cytokine quantification

\begin{tabular}{|c|c|c|c|c|}
\hline \multirow[t]{2}{*}{ Characteristic } & \multicolumn{2}{|c|}{$\mathrm{CP}$ cases } & \multicolumn{2}{|c|}{ Control } \\
\hline & Total (\%) & $M / F(n)$ & Total (\%) & $M / F(n)$ \\
\hline \multicolumn{5}{|l|}{ Type of CP } \\
\hline CP with spastic & $58(68.2)$ & $35 / 23$ & - & - \\
\hline CP without spastic & $27(31.8)$ & $19 / 8$ & - & - \\
\hline Total & $85(100)$ & $54 / 31$ & $75(100)$ & $62 / 13$ \\
\hline \multicolumn{5}{|l|}{ Gestational age } \\
\hline Term ( $\geq 37$ weeks) & $56(65.9)$ & $41 / 15$ & $70(93.3)$ & $57 / 13$ \\
\hline Preterm (<37 weeks) & $29(34.1)$ & $13 / 16$ & $5(6.7)$ & $5 / 0$ \\
\hline Total & $85(100)$ & $54 / 31$ & $75(100)$ & $62 / 13$ \\
\hline \multicolumn{5}{|l|}{ Birth weight } \\
\hline$\geq 2,500 \mathrm{~g}$ & $61(71.8)$ & $43 / 18$ & $71(94.7)$ & $59 / 12$ \\
\hline$<2,500 \mathrm{~g}$ & $24(28.2)$ & $11 / 13$ & $4(5.3)$ & $3 / 1$ \\
\hline Total & $85(100)$ & $54 / 31$ & $75(100)$ & $62 / 13$ \\
\hline \multicolumn{5}{|l|}{ Birth asphyxia } \\
\hline No asphyxia & $51(60.0)$ & $32 / 19$ & $73(97.3)$ & $61 / 12$ \\
\hline Asphyxia & $34(40.0)$ & $22 / 12$ & $2(2.7)$ & $1 / 1$ \\
\hline Total & $85(100)$ & $54 / 31$ & $75(100)$ & $62 / 13$ \\
\hline \multicolumn{5}{|l|}{ Complication } \\
\hline With PVL & $17(20.0)$ & $11 / 6$ & - & - \\
\hline Without PVL & $68(80.0)$ & $43 / 25$ & - & - \\
\hline With MR & $62(72.9)$ & $37 / 25$ & - & - \\
\hline Without MR & $23(27.1)$ & $17 / 6$ & - & - \\
\hline With HIE & $31(36.5)$ & $20 / 11$ & - & - \\
\hline Without HIE & $54(63.5)$ & $34 / 20$ & - & - \\
\hline \multicolumn{5}{|l|}{ Maternal factors } \\
\hline PROM & $19(22.4)$ & $8 / 11$ & $7(9.3)$ & $5 / 2$ \\
\hline No PROM & 66 (77.6) & $46 / 20$ & $68(90.7)$ & $57 / 11$ \\
\hline TPL & $20(23.5)$ & $15 / 5$ & $15(20.0)$ & $11 / 4$ \\
\hline No TPL & $65(76.5)$ & $39 / 26$ & $60(80.0)$ & $51 / 9$ \\
\hline $\mathrm{PIH}$ & $8(9.4)$ & $5 / 3$ & $6(8.0)$ & $5 / 1$ \\
\hline No PIH & 77 (90.6) & $49 / 28$ & $69(92.0)$ & $57 / 12$ \\
\hline
\end{tabular}

$\mathrm{CP}$, cerebral palsy; $\mathrm{M}$, male; $\mathrm{F}$, female; $\mathrm{PVL}$, periventricular leukomalacia; $\mathrm{MR}$, mental retardation; HIE, hypoxic ischemic encephalopathy; PROM, premature rupture of membrane; $\mathrm{TPL}$, threatened premature labor; $\mathrm{PIH}$, pregnancy-induced hypertension.

the analysis. For the serum IL- 6 assay, the age of the selected children ranged from 5 months to 36 months. Children with cough, fever, acute respiratory illness, or any other any indications of infection within the past 3 months were excluded. Because of the genetic factors and familial factors that are associated with CP, we ensured that the controls had no familial relationships with the patients and did not have neurological symptoms. Approval for the study was obtained from the ethics committee of Zhengzhou University and the Medical Academy of Henan Province (201201002) in accordance with the Declaration of Helsinki.
The database of medical records contains information on $\mathrm{CP}$ risk factors, such as birth asphyxia, symptoms concomitant with $\mathrm{CP}$, such as mental retardation (MR), neonatal complications, such as PVL, and on hypoxicischemic encephalopathy (HIE). In addition, the records contain information on maternal factors such as premature rupture of membrane (PROM), pregnancy-induced hypertension $(\mathrm{PIH})$, and threatening premature labor (TPL). Asphyxia was diagnosed using the criteria of the American Academy of Pediatrics and the American College of Obstetricians and Gynecologists, and newborns were included when at least three of the four criteria were met [15]. MR was identified based on a score of less than 70 on the Bayley Scales measurement of mental development index [16]. PVL was defined as parenchymal densities or lucencies around the ventricles during ultrasound examination of the head performed any time after 14 days post-birth [17], and this was further confirmed by MRI. Diagnosis of HIE required a combination of parameters that are indicative of metabolic acidosis within the first hours after birth. These include low umbilical cord blood $\mathrm{pH}(<7.0)$, a base deficit of over $12 \mathrm{mEq} / \mathrm{L}$, and evidence of a need for respiratory support starting in the first minutes after birth with low Apgar scores at and beyond $5 \mathrm{~min}$ after birth. The diagnosis of PROM was based on pooling of amniotic fluid in the vagina, amniotic fluid ferning patterns, and a positive nitrazine test [18]. PIH was diagnosed and classified according to the criteria recommended by the American Congress of Obstetricians and Gynecologists, including a systolic blood pressure of $140 \mathrm{mmHg}$ or higher or a diastolic blood pressure of $90 \mathrm{mmHg}$ or higher on two occasions at least $6 \mathrm{~h}$ apart occurring after 20 weeks of gestation in a pregnant woman with previously normal blood pressure and without detectable urinary protein [19]. TPL was based on at least one of the following having occurred during pregnancy: the mother was admitted to the hospital prenatally with an episode of TPL, the mother received antenatal steroids or tocolytics, or a note was made on the delivery room chart that there was a history of TPL during the pregnancy [20].

\section{Polymorphism selection}

A total of five SNPs (rs1800796, rs2069837, rs2066992, rs2069840, and rs10242595) of the $I L-6$ gene whose minor allele frequencies in the Chinese Han population are more than 0.1 were selected from the dbSNP database (www.ncbi.nlm.nih.gov/SNP) and the hapmap human SNP database (www.hapmap.org). All of rs2069837, rs2066992 in the second intron, and rs2069840 in the third intron are tag SNPs. rs1800796 and rs10242595 are located in the upstream and downstream regions of the $I L-6$ gene, respectively. 


\section{Genotyping}

Genomic DNA was prepared from venous blood using the AxyPrep Blood Genomic DNA Miniprep Kit (Axygen Biosciences, Union City, CA, USA) according to the manufacturer's instructions. Probes and primers were designed by the SEQUENOM online tools (https:// www.mysequenom.com) and the sequences are available upon request. After the amplification of polymorphismspanning fragments by multiplex polymerase chain reaction (PCR), the genotyping was performed with the Sequenom MassARRAY SNP genotyping platform (Sequenom, San Diego, CA, USA). The person who analyzed the genotype results was blinded to the clinical data.

\section{IL-6 quantification}

Blood samples were collected using EDTA as an anticoagulant. The samples were centrifuged at $1,500 \times g$ for $15 \mathrm{~min}$ at room temperature, and plasma was aliquoted and stored at $-70^{\circ} \mathrm{C}$. Before the assay, the frozen samples were thawed completely at room temperature, mixed well by vortexing, and centrifuged to remove precipitated material. IL-6 was assayed together with IL-8, IL-10, IL-17, TNF- $\alpha$, or IFN- $\gamma$ by using the Milliplex Human Cytokine/Chemokine Kits (Millipore, Billerica, MA, USA) according to the manufacturer's instructions on a Luminex 200IS System (Luminex Corporation, Austin, TX, USA). Quality control was performed between the plates by using the two controls provided in the kit and representative samples from both CP patients and controls run on all the plates. The assay was completed on the same day by the same person. The plate variation was $6.94 \%$ in this assay. IL-6 levels were calculated using the Beadview software package (Upstate, Temecula, CA, USA) and expressed as $\mathrm{pg} / \mathrm{mL}$. The detection limit for IL-6 was $0.3 \mathrm{pg} / \mathrm{mL}$.

\section{Statistical analysis}

For gene analysis, the Hardy-Weinberg equilibrium (HWE) test was performed on the allele and genotype frequency analysis using the SHEsis online software platform (http://analysis.bio-x.cn). Linkage disequilibrium was measured using standardized D', and the discrepancies in allele and genotype frequencies at single loci between patients and controls were compared using a Monte Carlo simulation strategy. The numbers of observations for each haplotype were compared using $X^{2}$ tests. The relative risk was approximated by the estimate of the odds ratio (OR). All ORs were adjusted for age and sex using logistic regression models. For each OR, a 95\% confidence interval (CI) was calculated. For IL-6 cytokine analysis, the Student's unpaired $t$-test was used. Data groups with unequal variances were analyzed using the Mann-Whitney U-test. All reported $P$ values were two-tailed and statistical significance was set at $P<0.05$. The Statistical Package for the Social Sciences (SPSS version 19.0) and Graphpad Prism 6.0 software package (version 6.0 for Windows, Graphpad, La Jolla, CA, USA) were used for all statistical analyses. For all comparisons, multiple testing on each individual SNP was corrected by the SNPSpD program (http://gump.qimr.edu.au/general/daleN/ matSpD/), which is based on the linkage disequilibrium information.

\section{Results}

\section{Overall analysis}

The genotypic distribution of the five selected SNPs in the controls was in HWE. There were no differences in allele or genotype frequencies between the total population of CP patients $(\mathrm{n}=713)$ and total population of controls $(\mathrm{n}=$ 753) for any of the five genetic polymorphisms (Table 3). Computation of D' indicated a strong linkage disequilibrium between these SNP markers ( $\mathrm{D}^{\prime}>0.8$ ) (Table 4). A haplotype analysis of all five SNPs between the CP and control subjects was performed (those with a haplotype frequency $<0.03$ were excluded from the analysis), and three common haplotypes were built. No differences in the haplotypes were found between $\mathrm{CP}$ cases and controls (data not shown).

\section{Subgroup analysis}

Subgroup analysis of SNPs was performed according to sex, gestational age, birth weight, birth asphyxia, subtypes of CP, pregnancy complications, and maternal factors. Significant differences in allele frequencies were observed between CP patients $(n=494)$ and controls $(n=491)$ in males for rs2069837 $(\mathrm{OR}=1.334,95 \% \mathrm{CI}=1.073-1.659$, $P=0.009, P=0.027$ after SNPSpD correction) (Table 5), but there were no differences in these SNP allele/genotype frequencies between $\mathrm{CP}$ patients and controls in females (data not shown).

Spastic CP was the main type of CP seen in this study population. Differences in allele frequencies were observed between spastic CP patients $(n=456)$ and controls $(n=$ 753) for rs2069837, but the difference disappeared after SNPSpD correction (data not shown). Further analysis according to the sex of the CP patients revealed significant differences in allele and genotype frequencies between male spastic CP patients $(n=325)$ and controls $(n=491)$ for rs1800796, rs2069837, and rs2066992, but the differences for rs1800796 and rs2066992 disappeared after SNPSpD correction (Table 6), which was similar to our previous analysis. Haplotype analysis for rs1800796, rs2069837, and rs2066992 showed that the haplotypes "CAT" and "GGG" (rs1800796, rs2069837, and rs2066992) were strongly associated with male spastic CP patients 
Table 3 Allele and genotype distribution of the five selected SNPs in cerebral palsy patients and controls

\begin{tabular}{|c|c|c|c|c|c|c|c|c|c|}
\hline \multirow[b]{2}{*}{ rs1800796 } & \multirow[t]{2}{*}{ Group } & \multicolumn{2}{|c|}{ Allele frequency } & \multirow[t]{2}{*}{$P$ value } & \multicolumn{3}{|c|}{ Genotype frequency } & \multirow[t]{2}{*}{$P$ value } & \multirow[t]{2}{*}{ Hardy-Weinberg equilibrium } \\
\hline & & C & G & & $\mathrm{C} / \mathrm{C}$ & $C / G$ & $\mathrm{G} / \mathrm{G}$ & & \\
\hline & Case & $977(0.690)$ & $439(0.310)$ & 0.256 & $347(0.490)$ & $283(0.400)$ & $78(0.110)$ & 0.300 & 0.081 \\
\hline & Control & $992(0.670)$ & $488(0.330)$ & & $334(0.451)$ & $324(0.438)$ & $82(0.111)$ & & 0.797 \\
\hline \multirow[t]{3}{*}{ rs2069837 } & & A & G & & $A / A$ & $A / G$ & $\mathrm{G} / \mathrm{G}$ & & \\
\hline & Case & $1138(0.807)$ & $272(0.193)$ & 0.062 & $469(0.665)$ & $200(0.284)$ & $36(0.051)$ & 0.144 & 0.018 \\
\hline & Control & $1134(0.779)$ & $322(0.221)$ & & $448(0.615)$ & $238(0.327)$ & $42(0.058)$ & & 0.169 \\
\hline \multirow[t]{3}{*}{ rs2066992 } & & G & T & & $\mathrm{G} / \mathrm{G}$ & $\mathrm{G} / \mathrm{T}$ & $T / T$ & & \\
\hline & Case & $441(0.311)$ & 977 (0.689) & 0.389 & $77(0.109)$ & $287(0.405)$ & $345(0.487)$ & 0.316 & 0.140 \\
\hline & Control & $483(0.326)$ & 999 (0.674) & & $77(0.104)$ & $329(0.444)$ & $335(0.452)$ & & 0.775 \\
\hline \multirow[t]{3}{*}{ rs2069840 } & & $C$ & G & & $\mathrm{C} / \mathrm{C}$ & $C / G$ & $\mathrm{G} / \mathrm{G}$ & & \\
\hline & Case & $1300(0.913)$ & $124(0.087)$ & 0.503 & $591(0.830)$ & $118(0.166)$ & $3(0.004)$ & 0.787 & 0.258 \\
\hline & Control & $1346(0.906)$ & $140(0.094)$ & & $607(0.817)$ & $132(0.178)$ & $4(0.005)$ & & 0.265 \\
\hline \multirow[t]{3}{*}{ rs10242595 } & & A & G & & A/A & $A / G$ & $\mathrm{G} / \mathrm{G}$ & & \\
\hline & Case & $1255(0.891)$ & 153 (0.109) & 0.435 & $560(0.795)$ & 135 (0.192) & $9(0.013)$ & 0.498 & 0.789 \\
\hline & Control & $1279(0.882)$ & $171(0.118)$ & & $569(0.785)$ & $141(0.194)$ & $15(0.021)$ & & 0.079 \\
\hline
\end{tabular}

(haplotypes with a frequency $<0.03$ were excluded from the analysis) (Table 7).

PVL is common in preterm brain injury and is related to the development of CP. In this study, we found differences in genotype frequencies between $\mathrm{CP}$ patients with PVL $(\mathrm{n}=56)$ and controls $(\mathrm{n}=491)$ in males at rs 1800796 and rs2066992 (Table 8). The haplotype analysis of all five analyzed SNPs did not show significant differences between CP patients with PVL and control subjects in either males or females.

According to gestational age at birth, the $\mathrm{CP}$ patients and controls were stratified as term or preterm $\mathrm{CP}$ cases. A difference in allele and genotype frequencies for the rs2069837 site was observed between term CP patients $(\mathrm{n}=338)$ and term controls $(\mathrm{n}=491)$ in males (Table 9), but no difference was found between preterm CP patients $(n=156)$ and preterm controls in males or between term and preterm $\mathrm{CP}$ patients in either males or females.

Differences in genotype frequencies were observed between CP patients with maternal PROM $(\mathrm{n}=88)$ and controls $(\mathrm{n}=753)$ for $\mathrm{rs} 2066992$ and rs1800796 (Table 10). Further analysis according to the sex of the CP patients showed differences between $\mathrm{CP}$ patients with maternal
PROM $(\mathrm{n}=88)$ and controls $(\mathrm{n}=491)$ in males for rs2066992 and rs1800796, but the differences disappeared after SNPSpD correction.

\section{IL-6 quantification}

The mean plasma IL-6 concentration was higher in the $\mathrm{CP}$ patients than in the controls, and this difference was more pronounced in males (Figure 1A). Subgroup analysis showed that the IL-6 level was higher in the spastic $\mathrm{CP}$ group compared to the control group (Figure 1B). Furthermore, the IL- 6 level in the CP patients was related to gestational age and a significant increase was seen in the full-term birth $\mathrm{CP}$ patients (Figure 1C). However, the IL-6 level was not changed compared to controls in the CP patients with PVL (Figure 1D). Further statistical analyses stratified by birth weight, birth asphyxia, MR, HIE, and maternal complications such as PIH, TPL, and PROM were also performed but no differences were found (data not shown). Furthermore, the plasma IL-6 levels were different between CP patients with genotypes CC and those with GG at rs1800796 $(P=0.033)$ (Figure $2 \mathrm{~A})$, and the plasma IL-6 levels of genotype CC at rs1800796 (Figure 2A), AA at rs2069837

Table 4 The linkage disequilibrium among the SNPs

\begin{tabular}{lccccc}
\hline $\mathbf{D}^{\prime} / \mathbf{r}^{\mathbf{2}}$ & rs1800796 & rs2069837 & rs2066992 & rs2069840 & rs10242595 \\
\hline rs1800796 & & 0.884 & 0.981 & 0.971 & 0.999 \\
rs2069837 & 0.463 & 0.903 & & 0.986 & 0.777 \\
rs2066992 & 0.948 & 0.497 & 0.211 & 0.912 \\
rs2069840 & 0.203 & 0.026 & 0.235 & 0.704 \\
rs10242595 & 0.228 & 0.025 & & \\
\hline
\end{tabular}

The standardized $\mathrm{D}^{\prime}$ values are shown above the diagonal, and the $r^{2}$ values are shown below the diagonal. 
Table 5 Allele and genotype distribution of the five selected SNPs in male cerebral palsy cases and controls

\begin{tabular}{|c|c|c|c|c|c|c|c|c|c|}
\hline \multirow[b]{2}{*}{ rs1800796 } & \multirow[t]{2}{*}{ Group } & \multicolumn{2}{|c|}{ Allele frequency } & \multirow[t]{2}{*}{$P$ value } & \multicolumn{3}{|c|}{ Genotype frequency } & \multirow[t]{2}{*}{$P$ value } & \multirow[t]{2}{*}{ Hardy-Weinberg equilibrium } \\
\hline & & C & G & & $\mathrm{C} / \mathrm{C}$ & $C / G$ & $\mathrm{G} / \mathrm{G}$ & & \\
\hline & Case & $678(0.690)$ & $304(0.310)$ & 0.092 & $242(0.493)$ & $194(0.395)$ & $55(0.112)$ & 0.113 & 0.093 \\
\hline & Control & $631(0.655)$ & $333(0.345)$ & & $206(0.427)$ & $219(0.454)$ & $57(0.118)$ & & 0.917 \\
\hline \multirow[t]{3}{*}{ rs2069837 } & & A & G & & A/A & $A / G$ & $\mathrm{G} / \mathrm{G}$ & & \\
\hline & Case & $790(0.808)$ & $188(0.192)$ & $0.009^{\mathrm{a}}$ & $326(0.667)$ & $138(0.282)$ & $25(0.051)$ & 0.041 & 0.044 \\
\hline & Control & $718(0.759)$ & $228(0.241)$ & & $279(0.590)$ & $160(0.338)$ & $34(0.072)$ & & 0.101 \\
\hline \multirow[t]{3}{*}{ rs2066992 } & & G & $\mathrm{T}$ & & $\mathrm{G} / \mathrm{G}$ & $\mathrm{G} / \mathrm{T}$ & $\mathrm{T} / \mathrm{T}$ & & \\
\hline & Case & $303(0.309)$ & $677(0.691)$ & 0.119 & $53(0.108)$ & $197(0.402)$ & $240(0.490)$ & 0.159 & 0.193 \\
\hline & Control & $330(0.342)$ & $634(0.658)$ & & $55(0.114)$ & $220(0.456)$ & 207 (0.429) & & 0.764 \\
\hline \multirow[t]{3}{*}{ rs2069840 } & & C & G & & $\mathrm{C} / \mathrm{C}$ & $C / G$ & $\mathrm{G} / \mathrm{G}$ & & \\
\hline & Case & $901(0.914)$ & $85(0.086)$ & 0.646 & $411(0.834)$ & $79(0.160)$ & $3(0.006)$ & 0.742 & 0.704 \\
\hline & Control & 877 (0.908) & $89(0.092)$ & & $396(0.820)$ & $85(0.176)$ & $2(0.004)$ & & 0.253 \\
\hline \multirow[t]{3}{*}{ rs10242595 } & & A & G & & $\mathrm{A} / \mathrm{A}$ & $A / G$ & $\mathrm{G} / \mathrm{G}$ & & \\
\hline & Case & $870(0.895)$ & $102(0.105)$ & 0.304 & $391(0.805)$ & $88(0.181)$ & $7(0.014)$ & 0.578 & 0.426 \\
\hline & Control & $838(0.880)$ & $114(0.120)$ & & $372(0.782)$ & $94(0.197)$ & $10(0.021)$ & & 0.168 \\
\hline
\end{tabular}

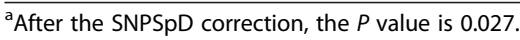

(Figure 2B), and TT at rs2066992 (Figure 2C) in CP patients were higher than in their respective controls. Therefore, we have sufficient evidence to assume that there is a positive association of the IL-6 gene with the etiology of CP.

\section{Discussion}

IL-6 is a proinflammatory cytokine that plays a key role in systemic inflammatory processes and has been identified as an important mediator of prenatal inflammation and CP. Clinical studies suggest that preterm neonates born to

Table 6 Allele and genotype distributions of the SNPs in male spastic cerebral palsy patients and controls

\begin{tabular}{|c|c|c|c|c|c|c|c|c|c|}
\hline \multirow[b]{2}{*}{ rs1800796 } & \multirow[t]{2}{*}{ Group } & \multicolumn{2}{|c|}{ Allele frequency } & \multirow[t]{2}{*}{$P$ value } & \multicolumn{3}{|c|}{ Genotype frequency } & \multirow[t]{2}{*}{$P$ value } & \multirow[t]{2}{*}{ Hardy-Weinberg equilibrium } \\
\hline & & C & G & & $\mathrm{C} / \mathrm{C}$ & $C / G$ & $\mathrm{G} / \mathrm{G}$ & & \\
\hline & Spastic & $458(0.709)$ & $188(0.291)$ & 0.022 & $169(0.523)$ & $120(0.372)$ & $34(0.105)$ & 0.027 & 0.073 \\
\hline & Non-spastic & $220(0.655)$ & $116(0.345)$ & 0.995 & $73(0.435)$ & $74(0.440)$ & $21(0.125)$ & 0.944 & 0.739 \\
\hline & Control & $631(0.655)$ & $333(0.345)$ & & $206(0.427)$ & $219(0.454)$ & $57(0.118)$ & & 0.917 \\
\hline \multirow[t]{4}{*}{ rs2069837 } & & A & G & & $A / A$ & $A / G$ & $\mathrm{G} / \mathrm{G}$ & & \\
\hline & Spastic & $524(0.816)$ & $118(0.184)$ & $0.007^{\mathrm{a}}$ & $220(0.685)$ & $84(0.262)$ & $17(0.053)$ & 0.024 & 0.022 \\
\hline & Non-spastic & $266(0.792)$ & $70(0.208)$ & 0.223 & $106(0.631)$ & $54(0.321)$ & $8(0.048)$ & 0.457 & 0.740 \\
\hline & Control & $718(0.759)$ & $228(0.241)$ & & $279(0.590)$ & $160(0.338)$ & $34(0.072)$ & & 0.101 \\
\hline \multirow[t]{4}{*}{ rs2066992 } & & G & $\mathrm{T}$ & & $\mathrm{G} / \mathrm{G}$ & $\mathrm{G} / \mathrm{T}$ & $\mathrm{T} / \mathrm{T}$ & & \\
\hline & Spastic & $189(0.293)$ & $455(0.707)$ & 0.040 & $34(0.106)$ & $121(0.376)$ & $167(0.519)$ & 0.041 & 0.092 \\
\hline & Non-spastic & $114(0.339)$ & $222(0.661)$ & 0.919 & $19(0.113)$ & $76(0.452)$ & $73(0.435)$ & 0.994 & 0.907 \\
\hline & Control & $330(0.342)$ & $634(0.658)$ & & $55(0.114)$ & $220(0.456)$ & 207 (0.429) & & 0.764 \\
\hline \multirow[t]{4}{*}{ rs2069840 } & & $C$ & G & & $\mathrm{C} / \mathrm{C}$ & $C / G$ & $\mathrm{G} / \mathrm{G}$ & & \\
\hline & Spastic & 599 (0.924) & $49(0.076)$ & 0.245 & $276(0.852)$ & $47(0.145)$ & $1(0.003)$ & 0.489 & 0.498 \\
\hline & Non-spastic & $302(0.893)$ & $36(0.107)$ & 0.440 & 135 (0.799) & $32(0.189)$ & $2(0.012)$ & 0.496 & 0.947 \\
\hline & Control & $877(0.908)$ & $89(0.092)$ & & $396(0.820)$ & $85(0.176)$ & $2(0.004)$ & & 0.253 \\
\hline \multirow[t]{4}{*}{ rs10242595 } & & A & G & & $\mathrm{A} / \mathrm{A}$ & $A / G$ & $\mathrm{G} / \mathrm{G}$ & & \\
\hline & Spastic & $575(0.901)$ & $63(0.099)$ & 0.192 & $261(0.818)$ & $53(0.166)$ & $5(0.016)$ & 0.444 & 0.235 \\
\hline & Non-spastic & $295(0.883)$ & $39(0.117)$ & 0.885 & 130 (0.778) & $35(0.210)$ & $2(0.012)$ & 0.729 & 0.835 \\
\hline & Control & $838(0.880)$ & $114(0.120)$ & & $372(0.782)$ & $94(0.197)$ & $10(0.021)$ & & 0.168 \\
\hline
\end{tabular}


Table 7 Estimated IL-6 haplotype frequencies

\begin{tabular}{lllll}
\hline Haplotype & Case (frequency) & Control (frequency) & $\boldsymbol{P}$ value & OR [95\% Cl] \\
\hline CAT & $446.99(0.705)$ & $586.16(0.634)$ & $0.011^{\mathrm{a}}$ & $1.331[1.068-1.659]$ \\
GGG & $113.50(0.179)$ & $202.19(0.219)$ & 0.039 & $0.764[0.591-0.987]$ \\
Global results & & & 0.037 & \\
\hline
\end{tabular}

Loci chosen for haplotype analysis: rs1800796, rs2069837, and rs2066992.

Haplotype frequency $<0.03$ in both controls and cases have been dropped.

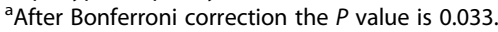

$\mathrm{OR}$, odds ratio; $\mathrm{Cl}$, confidence interval.

mothers with elevated IL-6 levels in the amniotic fluid are at increased risk for the subsequent development of PVL and CP [21], and CP patients show higher IL-6 levels in the cerebral spinal fluid [22]. Furthermore, infection has been shown to be an independent risk factor for spastic hemiplegia CP in infants born at term [23] and chorioamnionitis has been shown to be the most common cause of spastic quadriplegia CP [24]. In this study, we found that the plasma IL-6 levels were higher in CP patients than in controls and that IL-6 levels increased dramatically in spastic CP patients, which has not previously been reported. Overall, the findings from previous studies and our current work suggest that IL-6 is strongly associated with CP. Although we could not confirm whether the elevation of IL-6 levels is a recurrent or persistent issue that occurs after the event that led to the development of $\mathrm{CP}$ or if it is a transient effect during the late stage of CP; such increases might help to identify infants that could possibly benefit from later therapeutic interventions.

Genetic regulation of inflammation is an important biological risk factor that might contribute to the risk of developing CP [13]. The promoter region polymorphism rs1800795 (G-174C) in the $I L-6$ gene has been associated with $\mathrm{CP}$ in populations from both Australia [8] and California [12]. The variant C allele of rs1800795 (G-174C) has been shown to markedly increase the risk of hemiplegic $\mathrm{CP}$ and quadriplegic $\mathrm{CP}$ in infants [8], and the CC genotype

Table 8 Allele and genotype distributions of the SNPs in male cerebral palsy (CP) patients with or without periventricular leukomalacia (PVL)

\begin{tabular}{|c|c|c|c|c|c|c|c|c|c|}
\hline \multirow[b]{2}{*}{ rs1800796 } & \multirow[t]{2}{*}{ Group } & \multicolumn{2}{|c|}{ Allele frequency } & \multirow[t]{2}{*}{$P$ value } & \multicolumn{3}{|c|}{ Genotype frequency } & \multirow[t]{2}{*}{$P$ value } & \multirow[t]{2}{*}{ Hardy-Weinberg equilibrium } \\
\hline & & C & G & & $\mathrm{C} / \mathrm{C}$ & $C / G$ & $\mathrm{G} / \mathrm{G}$ & & \\
\hline & $C P+P V L$ & $80(0.714)$ & $32(0.286)$ & 0.206 & $33(0.589)$ & $14(0.250)$ & $9(0.161)$ & $0.014^{b}$ & 0.004 \\
\hline & $C P-P V L$ & $598(0.687)$ & $272(0.331)$ & 0.136 & $209(0.480)$ & $180(0.414)$ & $46(0.106)$ & 0.272 & 0.437 \\
\hline & Control & $631(0.655)$ & $333(0.345)$ & & $206(0.427)$ & $219(0.454)$ & $57(0.118)$ & & 0.917 \\
\hline \multirow[t]{4}{*}{ rs2069837 } & & A & G & & $\mathrm{A} / \mathrm{A}$ & $A / G$ & $\mathrm{G} / \mathrm{G}$ & & \\
\hline & $C P+P V L$ & $91(0.812)$ & $21(0.188)$ & 0.207 & $39(0.696)$ & $13(0.232)$ & $4(0.071)$ & 0.263 & 0.075 \\
\hline & $C P-P V L$ & $699(0.807)$ & $167(0.193)$ & $0.013^{\mathrm{a}}$ & $287(0.663)$ & $125(0.289)$ & $21(0.048)$ & 0.057 & 0.131 \\
\hline & Control & 718 (0.759) & $228(0.241)$ & & $279(0.590)$ & $160(0.338)$ & $34(0.072)$ & & 0.101 \\
\hline \multirow[t]{4}{*}{ rs2066992 } & & G & $\mathrm{T}$ & & $\mathrm{G} / \mathrm{G}$ & $\mathrm{G} / \mathrm{T}$ & $\mathrm{T} / \mathrm{T}$ & & \\
\hline & $C P+P V L$ & $32(0.286)$ & $80(0.714)$ & 0.230 & $9(0.161)$ & $14(0.250)$ & $33(0.589)$ & $0.013^{c}$ & 0.004 \\
\hline & $C P-P V L$ & $271(0.312)$ & $597(0.688)$ & 0.171 & $44(0.101)$ & $183(0.422)$ & $207(0.477)$ & 0.348 & 0.705 \\
\hline & Control & $330(0.342)$ & $634(0.658)$ & & $55(0.114)$ & $220(0.456)$ & 207 (0.429) & & 0.764 \\
\hline \multirow[t]{4}{*}{ rs2069840 } & & C & G & & $\mathrm{C} / \mathrm{C}$ & $C / G$ & $\mathrm{G} / \mathrm{G}$ & & \\
\hline & $\mathrm{CP}+\mathrm{PVL}$ & 105 (0.938) & $7(0.062)$ & 0.554 & 49 (0.875) & $7(0.125)$ & $0(0.000)$ & 0.554 & 0.618 \\
\hline & $C P-P V L$ & 796 (0.911) & $78(0.890)$ & 0.830 & $362(0.828)$ & $72(0.165)$ & $3(0.007)$ & 0.778 & 0.777 \\
\hline & Control & 877 (0.908) & $89(0.092)$ & & $396(0.820)$ & 85 (0.176) & $2(0.004)$ & & 0.253 \\
\hline \multirow[t]{4}{*}{ rs10242595 } & & A & G & & A/A & $A / G$ & $\mathrm{G} / \mathrm{G}$ & & \\
\hline & $C P+P V L$ & $99(0.900)$ & $11(0.100)$ & 0.543 & $45(0.818)$ & $9(0.164)$ & $1(0.018)$ & 0.821 & 0.500 \\
\hline & $C P-P V L$ & 771 (0.894) & $91(0.106)$ & 0.341 & 346 (0.803) & 79 (0.183) & $6(0.014)$ & 0.603 & 0.542 \\
\hline & Control & $838(0.880)$ & $114(0.120)$ & & $372(0.782)$ & $94(0.197)$ & $10(0.021)$ & & 0.168 \\
\hline
\end{tabular}

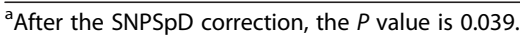

${ }^{\mathrm{b}}$ After the SNPSpD correction, the $P$ value is 0.042 .

${ }^{C}$ After the SNPSpD correction, the $P$ value is 0.039 . 
Table 9 Allele and genotype distributions of the SNPs in male term cerebral palsy patients and controls

\begin{tabular}{|c|c|c|c|c|c|c|c|c|c|}
\hline \multirow{2}{*}{ rs1800796 } & \multirow[t]{2}{*}{ Group } & \multicolumn{2}{|c|}{ Allele frequency } & \multirow[t]{2}{*}{$P$ value } & \multicolumn{3}{|c|}{ Genotype frequency } & \multirow[t]{2}{*}{$P$ value } & \multirow[t]{2}{*}{ Hardy-Weinberg equilibrium } \\
\hline & & C & G & & $\mathrm{C} / \mathrm{C}$ & $C / G$ & $\mathrm{G} / \mathrm{G}$ & & \\
\hline & Case & $463(0.689)$ & $209(0.311)$ & 0.137 & $162(0.482)$ & $139(0.414)$ & $35(0.104)$ & 0.282 & 0.525 \\
\hline & Control & $617(0.654)$ & $327(0.346)$ & & $20(0.426)$ & $215(0.456)$ & $56(0.119)$ & & 0.897 \\
\hline \multirow[t]{3}{*}{ rs2069837 } & & A & G & & A/A & $A / G$ & $\mathrm{G} / \mathrm{G}$ & & \\
\hline & Case & $540(0.811)$ & $126(0.189)$ & $0.012^{\mathrm{a}}$ & $220(0.661)$ & $100(0.300)$ & $13(0.039)$ & 0.046 & 0.699 \\
\hline & Control & $702(0.758)$ & $224(0.242)$ & & $272(0.587)$ & $158(0.341)$ & $33(0.071)$ & & 0.134 \\
\hline \multirow[t]{3}{*}{ rs2066992 } & & G & $\mathrm{T}$ & & $\mathrm{G} / \mathrm{G}$ & $\mathrm{G} / \mathrm{T}$ & $\mathrm{T} / \mathrm{T}$ & & \\
\hline & Case & $209(0.312)$ & $461(0.688)$ & 0.203 & $33(0.099)$ & $143(0.427)$ & $159(0.475)$ & 0.430 & 0.918 \\
\hline & Control & $323(0.342)$ & $621(0.658)$ & & $54(0.114)$ & $215(0.456)$ & $203(0.430)$ & & 0.797 \\
\hline \multirow[t]{3}{*}{ rs2069840 } & & $C$ & G & & $C / C$ & $C / G$ & $\mathrm{G} / \mathrm{G}$ & & \\
\hline & Case & $610(0.905)$ & $64(0.095)$ & 0.838 & 276 (0.819) & $58(0.172)$ & $3(0.009)$ & 0.701 & 0.980 \\
\hline & Control & 859 (0.908) & $87(0.092)$ & & $388(0.820)$ & $83(0.175)$ & $2(0.004)$ & & 0.271 \\
\hline \multirow[t]{3}{*}{ rs10242595 } & & A & G & & $\mathrm{A} / \mathrm{A}$ & $A / G$ & $\mathrm{G} / \mathrm{G}$ & & \\
\hline & Case & $595(0.891)$ & $73(0.109)$ & 0.544 & $266(0.796)$ & $63(0.189)$ & $5(0.015)$ & 0.769 & 0.570 \\
\hline & Control & $821(0.881)$ & 111 (0.119) & & $365(0.783)$ & $91(0.195)$ & $10(0.021)$ & & 0.134 \\
\hline
\end{tabular}

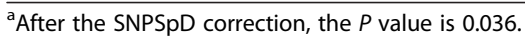

Table 10 Allele and genotype distributions of the SNPs in patients with or without maternal premature rupture of membrane (PROM)

\begin{tabular}{|c|c|c|c|c|c|c|c|c|c|}
\hline \multirow{2}{*}{ rs1800796 } & \multirow[t]{2}{*}{ Group } & \multicolumn{2}{|c|}{ Allele frequency } & \multirow[t]{2}{*}{$P$ value } & \multicolumn{2}{|c|}{ Genotype frequency } & \multirow[b]{2}{*}{$\mathrm{G} / \mathrm{G}$} & \multirow[t]{2}{*}{$P$ value } & \multirow[t]{2}{*}{ Hardy-Weinberg equilibrium } \\
\hline & & C & G & & $\mathrm{C} / \mathrm{C}$ & $C / G$ & & & \\
\hline & $\mathrm{CP}+\mathrm{PROM}$ & $121(0.695)$ & $53(0.305)$ & 0.504 & $49(0.563)$ & $23(0.264)$ & $15(0.172)$ & $0.006^{\mathrm{a}}$ & 0.001 \\
\hline & $\mathrm{CP}-\mathrm{PROM}$ & $856(0.689)$ & $386(0.311)$ & 0.292 & $298(0.480)$ & $260(0.419)$ & $63(0.101)$ & 0.560 & 0.572 \\
\hline & Control & $992(0.670)$ & $488(0.330)$ & & $334(0.451)$ & $324(0.438)$ & $82(0.111)$ & $0.011^{* b}$ & 0.797 \\
\hline \multirow[t]{4}{*}{ rs2069837 } & & A & G & & $A / A$ & $A / G$ & $\mathrm{G} / \mathrm{G}$ & & \\
\hline & $\mathrm{CP}+\mathrm{PROM}$ & $145(0.824)$ & $31(0.176)$ & 0.171 & $62(0.705)$ & $21(0.239)$ & $5(0.057)$ & 0.231 & 0.095 \\
\hline & $\mathrm{CP}-\mathrm{PROM}$ & $993(0.805)$ & $241(0.195)$ & 0.101 & $407(0.660)$ & $179(0.290)$ & $31(0.050)$ & 0.243 & 0.056 \\
\hline & Control & $1134(0.779)$ & $322(0.221)$ & & $448(0.615)$ & $238(0.327)$ & $42(0.058)$ & & 0.169 \\
\hline \multirow[t]{4}{*}{ rs2066992 } & & G & T & & $\mathrm{G} / \mathrm{G}$ & $\mathrm{G} / \mathrm{T}$ & $\mathrm{T} / \mathrm{T}$ & & \\
\hline & $\mathrm{CP}+\mathrm{PROM}$ & $54(0.307)$ & $122(0.693)$ & 0.609 & $15(0.170)$ & $24(0.273)$ & $49(0.557)$ & $0.005^{c}$ & 0.001 \\
\hline & $\mathrm{CP}-\mathrm{PROM}$ & 387 (0.312) & 855 (0.688) & 0.425 & $62(0.100)$ & $263(0.424)$ & $296(0.477)$ & 0.663 & 0.750 \\
\hline & Control & $483(0.326)$ & 999 (0.674) & & $77(0.104)$ & $329(0.444)$ & $335(0.452)$ & $0.012^{* d}$ & 0.775 \\
\hline \multirow[t]{4}{*}{ rs2069840 } & & $C$ & G & & $C / C$ & $C / G$ & $\mathrm{G} / \mathrm{G}$ & & \\
\hline & $\mathrm{CP}+\mathrm{PROM}$ & $163(0.926)$ & $13(0.0734$ & 0.377 & $75(0.852)$ & $13(0.148)$ & $0(0.000)$ & 0.607 & 0.454 \\
\hline & $\mathrm{CP}-\mathrm{PROM}$ & $1137(0.911)$ & $111(0.089)$ & 0.635 & $516(0.827)$ & $105(0.168)$ & $3(0.005)$ & 0.889 & 0.339 \\
\hline & Control & $1346(0.906)$ & $140(0.094)$ & & $607(0.817)$ & $132(0.178)$ & $4(0.005)$ & & 0.265 \\
\hline \multirow[t]{4}{*}{ rs10242595 } & & A & G & & $\mathrm{A} / \mathrm{A}$ & $\mathrm{A} / \mathrm{G}$ & $\mathrm{G} / \mathrm{G}$ & & \\
\hline & $\mathrm{CP}+\mathrm{PROM}$ & 153 (0.879) & $21(0.121)$ & 0.915 & $68(0.782)$ & $17(0.195)$ & $2(0.023)$ & 0.990 & 0.459 \\
\hline & $C P-P R O M$ & $1102(0.893)$ & $132(0.107)$ & 0.371 & $492(0.797)$ & $118(0.191)$ & $7(0.011)$ & 0.395 & 0.980 \\
\hline & Control & $1279(0.882)$ & $171(0.118)$ & & $569(0.785)$ & $141(0.194)$ & $15(0.021)$ & & 0.079 \\
\hline
\end{tabular}

*Comparison between total CP patients with maternal PROM and without PROM.

${ }^{a}$ After the SNPSpD correction, the $P$ value is 0.0018 .

${ }^{\mathrm{b}}$ After the SNPSpD correction, the $P$ value is 0.033 .

${ }^{c}$ After the SNPSpD correction, the $P$ value is 0.015 .

${ }^{\mathrm{d}}$ After the SNPSpD correction, the $P$ value is 0.036 . 

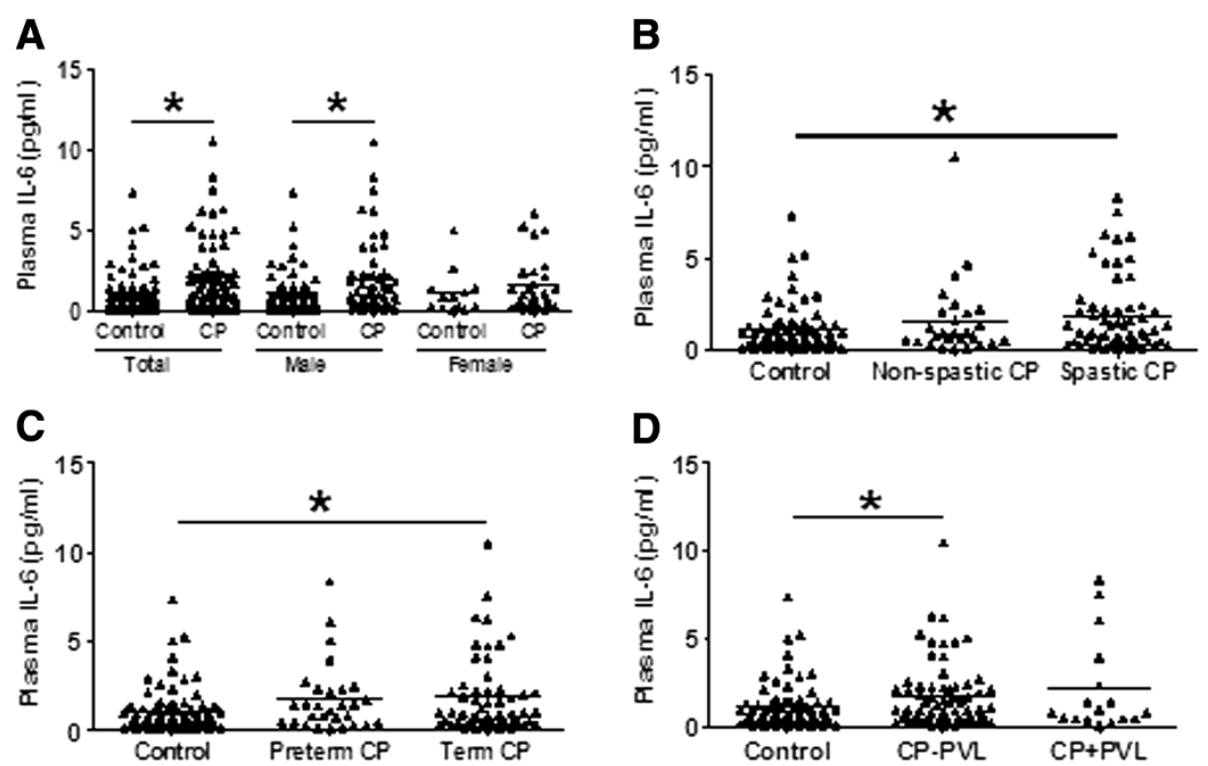

Figure 1 Plasma IL-6 concentrations in CP patients and controls. (A) Distribution of plasma IL-6 concentrations between total CP patients (85 patients) and total controls (75 participants) and between subgroups analyzed by sex. (B) Plasma IL-6 concentrations among spastic CP patients (58 patients), non-spastic CP patients (27 patients), and controls. (C) Plasma concentrations among term CP patients (56 patients), preterm CP patients (29 patients), and controls. (D) Plasma IL-6 concentrations among CP patients with PVL (17 patients), CP patients without PVL (68 patients), and controls. Each dot represents one patient and each bar represents the mean value. ${ }^{*} P<0.05$; Mann-Whitney U-test. CP, cerebral palsy; PVL, periventricular leukomalacia.

of the $174 \mathrm{C} / \mathrm{G}$ variation is related to higher levels of IL6 compared to the GG genotype [25].

Studies of $I L-6$ polymorphisms have mainly focused on rs1800795 [8,12], but this polymorphism is absent in the Han Chinese population [26]. The SNPs rs1800796, rs2069837, and rs10242595 have all been reported to be associated with Alzheimer's disease and ischemic stroke [27-30], and the rs2069840 SNP has been shown to be associated with systemic sclerosis [31]. The common haplotype tagged by the SNP rs1800796 (C-572G) has
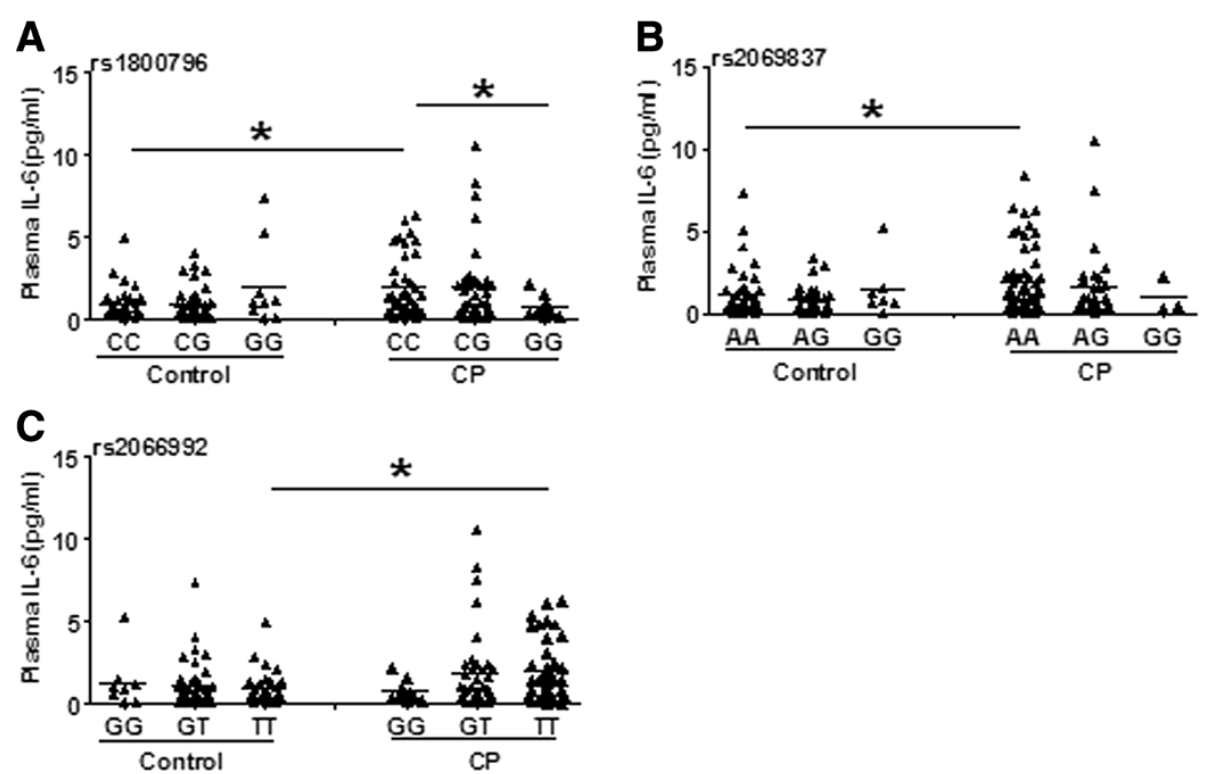

Figure 2 Comparison of genotypes and plasma IL-6 levels in CP patients and controls. (A) The comparison at rs1800796. (B) The comparison at rs2069837. (C) The comparison at rs2066992. Each dot represents one patient and each bar represents the mean value. ${ }^{*} P<0.05$; Mann-Whitney U-test. CP, cerebral palsy. 
been shown to be associated with an increased risk of brain infarct in elderly subjects in a cardiovascular health study [32]. Even though these SNPs were associated with neurological disease in adults, so far there has been no evidence showing an association with CP. This study has, for the first time, shown that associations between $I L-6$ polymorphisms and $\mathrm{CP}$ are related to sex, PVL, gestational age, and the clinical subtype of CP. The rs2069837 SNP is associated with male spastic CP patients born at full term, and the genotypes of rs1800796 and rs2066992 are associated with male CP patients with PVL.

The genotypes produced from rs1800796 and rs2066992 SNPs, however, showed deviation from HWE in CP patients with PVL. Deviations from HWE could point to a sampling bias, mistyping of genotypes, or spurious gene associations after population stratification [33]. We carefully re-analyzed the data based on the reasons mentioned above and found that all of the controls were in HWE. As Esser suggested, if only the genotype distribution of the patient group shows deviation from HWE, this might provide additional support for an association between the marker locus with the disease in question [33]. Therefore, our study showed that the genotypes produced from the two SNPs (rs1800796 and rs2066992) are more likely associated with male CP patients with PVL. On the other hand, we cannot exclude the potential problem of a small sample size $(\mathrm{n}=56)$ after population stratification.

In addition to changes in SNP frequency, we also measured IL-6 levels directly and found that in CP patients the CC genotype of rs1800796 (C-572G) has an effect on serum levels of IL-6 compared to the GG genotype. This is similar to what has been seen in trauma patients carrying the $-572 \mathrm{C}$ allele or $-572 \mathrm{G}$ allele [34]. This suggests that the $\mathrm{G}$ allele of rs1800796 could reduce transcriptional activity of the IL- 6 promoter. We also found that the plasma IL-6 levels of genotype CC at rs1800796, AA at rs2069837, and TT at rs2066992 in CP patients were higher than their respective controls. We speculate that the genetic variation might enhance or weaken the inflammatory response to some extent during the pathogenic process of $\mathrm{CP}$, or it might influence the interaction between genetic factors and the environment. It seems that the $\mathrm{C}$ allele of rs1800796, the A allele of rs2069837, and the T allele of rs2066992 might be risk factors for CP. This must be further confirmed with even larger samples.

In this study population, $69.3 \%(494 / 713)$ of the CP patients were males, and this proportion is in accordance with reports from other nations [35-38]. This sexrelated difference has also been noticed in in vitro and in vivo models of cerebral ischemia and neuronal injury [39]. However, even though sex hormones, such as estrogens, protect against brain injury [40], the circulating hormone levels cannot completely account for sex differences in the CP patients or in the developing brain [41]. This could be related to genetic background since it has been reported that female-derived neurons (XX) have a survival advantage compared with male-derived neurons (XY) [42].

PROM has been associated with increased risk for intrauterine infection and clinical chorioamnionitis [43,44], and it has been observed that infants born after PROM are at increased risk of white matter injury and subsequent CP diagnosis $[45,46]$. In our study, we found that the genotypes of SNPs rs1800796 and rs2066992 are associated with $\mathrm{CP}$ and that this association is more robust in $\mathrm{CP}$ patients with maternal PROM. This finding suggests that maternal infections can be an up-stream causative factor that contributes to $\mathrm{CP}$.

In summary, our study suggests that IL-6 participates in the pathogenesis of $\mathrm{CP}$ in a sex-related manner and that $I L-6$ gene polymorphisms are risk markers for male term infants and might be related to the development of PVL in male CP patients.

\section{Abbreviations}

Cl: Confidence interval; CP: Cerebral palsy; HIE: Hypoxic-ischemic encephalopathy; HWE: Hardy-Weinberg equilibrium; IL-6: Interleuken-6; MR: Mental retardation; OR: Odds ratio; PCR: Polymerase chain reaction; PIH: Pregnancy-induced hypertension; PROM: Premature rupture of membrane; PVL: Periventricular leukomalacia; SNPs: Single nucleotide polymorphisms; TPL: Threatening premature labor.

\section{Competing interests}

The authors declare that they have no competing interests.

\section{Authors' contributions}

$\mathrm{CZ}$ and $\mathrm{QX}$ conceived the project. DB, TL, QS, DZ, XZ, and $L X$ provided samples. HW, MC, and DB performed most of the experiments. DB, HW, and MC analyzed the data. DZ and QS provided support when collecting samples. XW, LH, and KB provided support for the project and valuable discussions. DB, CZ, and QX wrote the paper. All authors read and made comments on the manuscript during its drafting. All authors read and approved the final manuscript.

\section{Acknowledgements}

We are grateful to all of the participants in this study. This work was supported by grants from the National Natural Science Foundation of China (No: 81261120400, 31271152, 90919049, 812111098, and 61240031), the 973 Program (2011CB504501), the National Health and Family Planning Commission of China (201002006), the Health Department of Henan Province, the Department of Science and Technology of Henan Province (134200510023), the Department of Science and Technology of Zhengzhou, the Swedish Research Council (VR), the Swedish Medical Society, and Swedish governmental grants to scientists working in health care (ALF).

\section{Author details}

${ }^{1}$ Department of Pediatrics, The Third Affiliated Hospital of Zhengzhou University, 7 Kangfu Street, 450052 Zhengzhou, China. ${ }^{2}$ Children's Hospital and Institutes of Biomedical Sciences, Fudan University, 130 Dong'an Road, 200032 Shanghai, China. ${ }^{3}$ Department of Pediatrics, Zhengzhou Children's Hospital, 255 Gangdu Street, 450053 Zhengzhou, China. ${ }^{4}$ Department of Women's and Children's Health, Karolinska University Hospital, Q2:07, 17176 Stockholm, Sweden. ${ }^{5}$ Center for Brain Repair and Rehabilitation, University of Gothenburg, 11 Medicinaregatan, SE-40530 Gothenburg, Sweden. 'Bio-X Institutes, Key Laboratory for the Genetics of Developmental and Neuropsychiatric Disorders, Shanghai Jiaotong University, 1954 Huashan Road, 200030 Shanghai, China. ${ }^{7}$ Perinatal Center, Institute of Neuroscience and Physiology, University of Gothenburg, 11 Medicinaregatan, 40530 Gothenburg, Sweden. 
Received: 9 January 2014 Accepted: 19 May 2014

Published: 6 June 2014

\section{References}

1. Wu YW, Croen LA, Vanderwerf A, Gelfand AA, Torres AR: Candidate genes and risk for CP: a population-based study. Pediatr Res 2011, 70:642-646.

2. Cheng X, Li T, Wang H, Zhu D, Ma C, Ma B, Wang Y, Zhang J, Guo L, Wang L, Yun L, Chen S, Jiang Z, He L, Zhu C, Xing Q: Methylenetetrahydrofolate reductase gene polymorphisms and cerebral palsy in Chinese infants. J Hum Genet 2011, 56:17-21.

3. Pennington L, Virella D, Mjoen T, Da Graca AM, Murray J, Colver A, Himmelmann K, Rackauskaite G, Greitane A, Prasauskiene A, Andersen G, de la Cruz J: Development of The Viking Speech Scale to classify the speech of children with cerebral palsy. Res Dev Disabil 2013, 34:3202-3210.

4. Tator C, Bray G, Morin D: The CBANCH report-the burden of neurological diseases, disorders, and injuries in Canada. Can J Neuro Sci 2007, 34:268-269.

5. Tatla SK, Sauve K, Virji-Babul N, Holsti L, Butler C, Van Der Loos HF: Evidence for outcomes of motivational rehabilitation interventions for children and adolescents with cerebral palsy: an American Academy for cerebral palsy and developmental medicine systematic review. Dev Med Child Neurol 2013, 55:593-601.

6. Jacobsson B, Hagberg G: Antenatal risk factors for cerebral palsy. Best Pract Res Clin Obstet Gynaecol 2004, 18:425-436.

7. Elovitz MA, Brown AG, Breen K, Anton L, Maubert M, Burd I: Intrauterine inflammation, insufficient to induce parturition, still evokes fetal and neonatal brain injury. Int J Dev Neurosci 2011, 29:663-671.

8. Djukic M, Gibson CS, Maclennan AH, Goldwater PN, Haan EA, McMichael G, Priest K, Dekker GA, Hague WM, Chan A, Rudzki Z, VAN Essen P, Khong TY, Morton MR, Ranieri E, Scott H, Tapp H, Casey G: Genetic susceptibility to viral exposure may increase the risk of cerebral palsy. Aust N Z J Obstet Gynaecol 2009, 49:247-253.

9. Resch B, Radinger A, Mannhalter C, Horvath B, Binder A, Zenz W, Walcher W, Haas J, Muller WD, Pertl B: Maternal interleukin-6 (-174) C/C polymorphism is associated with chorioamnionitis and cystic periventricular leucomalacia of the preterm infant. J Perinatol 2010, 30:712-716.

10. Chen M, Li T, Lin S, Bi D, Zhu D, Shang Q, Ma C, Wang H, Wang L, Zhang Y, Zhang Y, He L, Zhu C, Xing Q: Association of interleukin 6 gene polymorphisms with genetic susceptibilities to spastic tetraplegia in males: a case-control study. Cytokine 2013, 61:826-830.

11. Harding DR, Dhamrait S, Whitelaw A, Humphries SE, Marlow N, Montgomery HE: Does interleukin-6 genotype influence cerebral injury or developmental progress after preterm birth? Pediatrics 2004, 114:941-947.

12. Wu YW, Croen LA, Torres AR, Van De Water J, Grether JK, Hsu NN: Interleukin- 6 genotype and risk for cerebral palsy in term and near-term infants. Ann Neurol 2009, 66:663-670.

13. Kapitanovic Vidak H, Catela Ivkovic T, Jokic M, Spaventi R, Kapitanovic S: The association between proinflammatory cytokine polymorphisms and cerebral palsy in very preterm infants. Cytokine 2012, 58:57-64.

14. Sellier E, Surman G, Himmelmann K, Andersen G, Colver A, Krageloh-Mann I, De-la-Cruz J, Cans C: Trends in prevalence of cerebral palsy in children born with a birthweight of 2,500 g or over in Europe from 1980 to 1998. Eur J Epidemiol 2010, 25:635-642.

15. Avasiloaiei A, Dimitriu C, Moscalu M, Paduraru L, Stamatin M: High-dose phenobarbital or erythropoietin for the treatment of perinatal asphyxia in term newborns. Pediatr Int 2013, 55:589-593.

16. Zhu C, Kang W, Xu F, Cheng X, Zhang Z, Jia L, Ji L, Guo X, Xiong H, Simbruner G, Blomgren K, Wang X: Erythropoietin improved neurologic outcomes in newborns with hypoxic-ischemic encephalopathy. Pediatrics 2009, 124:e218-e226

17. Soraisham AS, Trevenen C, Wood S, Singhal N, Sauve R: Histological chorioamnionitis and neurodevelopmental outcome in preterm infants. $J$ Perinatol 2013, 33:70-75.

18. Ferrell G, Lu M, Stoddard P, Sammel MD, Romero R, Strauss JF 3rd, Matthews CA: A single nucleotide polymorphism in the promoter of the LOXL1 gene and its relationship to pelvic organ prolapse and preterm premature rupture of membranes. Reprod Sci 2009, 16:438-446.

19. Practice ACOO: ACOG practice bulletin. Diagnosis and management of preeclampsia and eclampsia. Number 33, January 2002. American College of Obstetricians and Gynecologists. Int J Gynaecol Obstet 2002, 77:67-75.
20. Campbell MK, Cartier S, Xie B, Kouniakis G, Huang W, Han V: Determinants of small for gestational age birth at term. Paediatr Perinat Epidemiol 2012, 26:525-533.

21. Smith SE, Li J, Garbett K, Mirnics K, Patterson PH: Maternal immune activation alters fetal brain development through interleukin-6. J Neurosci 2007, 27:10695-10702.

22. Yoon BH, Park CW, Chaiworapongsa T: Intrauterine infection and the development of cerebral palsy. BJOG 2003, 110(Suppl 20):124-127.

23. Ahlin K, Himmelmann K, Hagberg G, Kacerovsky M, Cobo T, Wennerholm $U B$, Jacobsson B: Cerebral palsy and perinatal infection in children born at term. Obstet Gynecol 2013, 122:41-49.

24. Odding E, Roebroeck ME, Stam HJ: The epidemiology of cerebral palsy: incidence, impairments and risk factors. Disabil Rehabil 2006, 28:183-191.

25. Crider KS, Whitehead N, Buus RM: Genetic variation associated with preterm birth: a HuGE review. Genet Med 2005, 7:593-604.

26. International HapMap Consortium: The International HapMap Project. Nature 2003, 426:789-796.

27. He MX, Yang WL, Zhang MM, Lian YJ, Hua HY, Zeng JS, Zhang LR: Association between interleukin- 6 gene promoter $-572 \mathrm{C} / \mathrm{G}$ polymorphism and the risk of sporadic Alzheimer's disease. Neurol Sci 2010, 31:165-168

28. Ma Y, Tang RK, Yang X, Peng GG, Liu Y, Wang XM, Wu BH, Yu JM: Lack of an association between interleukin- 6 gene promoter polymorphisms $(-174 \mathrm{G} / \mathrm{C},-572 \mathrm{G} / \mathrm{C})$ and ischemic heart disease and/or ischemic stroke: a meta-analysis. Hum Immunol 2011, 72:641-651.

29. Combarros O, Van Duijn CM, Hammond N, Belbin O, Arias-Vasquez A, CortinaBorja M, Lehmann MG, Aulchenko YS, Schuur M, Kolsch H, Heun R, Wilcock GK, Brown K, Kehoe PG, Harrison R, Coto E, Alvarez V, Deloukas P, Mateo I, Gwilliam R, Morgan K, Warden DR, Smith AD, Lehmann DJ: Replication by the Epistasis Project of the interaction between the genes for IL- 6 and IL-10 in the risk of Alzheimer's disease. J Neuroinflammation 2009, 6:22.

30. Manso H, Krug T, Sobral J, Albergaria I, Gaspar G, Ferro JM, Oliveira SA, Vicente AM: Variants in the inflammatory IL6 and MPO genes modulate stroke susceptibility through main effects and gene-gene interactions. J Cereb Blood Flow Metab 2011, 31:1751-1759.

31. Cenit MC, Simeon CP, Vonk MC, Callejas-Rubio JL, Espinosa G, Carreira P, Blanco FJ, Narvaez J, Tolosa C, Roman-Ivorra JA, Gómez-García I, García-Hernández FJ, Gallego M, García-Portales R, Egurbide MV, Fonollosa V, García de la Peña P, López-Longo FJ, González-Gay MA, Spanish Scleroderma Group, Hesselstrand R, Riemekasten G, Witte T, Voskuyl AE, Schuerwegh AJ, Madhok R, Fonseca C, Denton C, Nordin A, Palm OØ, et al: Influence of the IL6 gene in susceptibility to systemic sclerosis. J Rheumatol 2012, 39:2294-2302.

32. Fornage M, Chiang YA, O'Meara ES, Psaty BM, Reiner AP, Siscovick DS, Tracy RP, Longstreth WT Jr: Biomarkers of inflammation and MRI-Defined small vessel disease of the brain: the Cardiovascular Health Study. Stroke 2008, 39:1952-1959.

33. Esser C, Tomluk J: Reporting Hardy-Weinberg tests in case-control studies: reasons for caution but not for panic reactions. J Invest Dermatol 2005, 124:1082-1083.

34. Gu W, Du DY, Huang J, Zhang LY, Liu Q, Zhu PF, Wang ZG, Jiang JX: Identification of interleukin-6 promoter polymorphisms in the Chinese Han population and their functional significance. Crit Care Med 2008, 36:1437-1443.

35. Tosun A, Gokben S, Serdaroglu G, Polat M, Tekgul H: Changing views of cerebral palsy over 35 years: the experience of a center. Turk J Pediatr 2013, 55:8-15.

36. Serdaroglu A, Cansu A, Ozkan S, Tezcan S: Prevalence of cerebral palsy in Turkish children between the ages of 2 and 16 years. Dev Med Child Neurol 2006, 48:413-416.

37. Himmelmann K, Hagberg G, Beckung E, Hagberg B, Uvebrant P: The changing panorama of cerebral palsy in Sweden. IX. Prevalence and origin in the birth-year period 1995-1998. Acta Paediatr 2005, 94:287-294.

38. Stelmach T, Pisarev H, Talvik T: Ante- and perinatal factors for cerebral palsy: case-control study in Estonia. J Child Neurol 2005, 20:654-660.

39. Lang JT, McCullough LD: Pathways to ischemic neuronal cell death: are sex differences relevant? J Transl Med 2008, 6:33.

40. Johnston MV, Hagberg H: Sex and the pathogenesis of cerebral palsy. Dev Med Child Neurol 2007, 49:74-78.

41. Golomb MR, Fullerton HJ, Nowak-Gottl U, Deveber G, International Pediatric Stroke Study G: Male predominance in childhood ischemic stroke: findings from the international pediatric stroke study. Stroke 2009, 40:52-57. 
42. Zhang L, Li PP, Feng X, Barker JL, Smith SV, Rubinow DR: Sex-related differences in neuronal cell survival and signaling in rats. Neurosci Lett 2003, 337:65-68.

43. Romero R, Gotsch F, Pineles B, Kusanovic JP: Inflammation in pregnancy: its roles in reproductive physiology, obstetrical complications, and fetal injury. Nutr Rev 2007, 65:S194-S202.

44. Wang H, Parry S, Macones G, Sammel MD, Ferrand PE, Kuivaniemi H, Tromp G, Halder I, Shriver MD, Romero R, Strauss JF 3rd: Functionally significant SNP MMP8 promoter haplotypes and preterm premature rupture of membranes (PPROM). Hum Mol Genet 2004, 13:2659-2669.

45. Jacobsson B, Hagberg G, Hagberg B, Ladfors L, Niklasson A, Hagberg H: Cerebral palsy in preterm infants: a population-based case-control study of antenatal and intrapartal risk factors. Acta Paediatr 2002, 91:946-951.

46. McElrath TF, Allred EN, Boggess KA, Kuban K, O'Shea TM, Paneth N, Leviton A, Investigators ES: Maternal antenatal complications and the risk of neonatal cerebral white matter damage and later cerebral palsy in children born at an extremely low gestational age. Am J Epidemiol 2009, 170:819-828.

doi:10.1186/1742-2094-11-100

Cite this article as: Bi et al:: The association between sex-related interleukin- 6 gene polymorphisms and the risk for cerebral palsy. Journal of Neuroinflammation 2014 11:100.

\section{Submit your next manuscript to BioMed Central and take full advantage of:}

- Convenient online submission

- Thorough peer review

- No space constraints or color figure charges

- Immediate publication on acceptance

- Inclusion in PubMed, CAS, Scopus and Google Scholar

- Research which is freely available for redistribution 